\title{
Improvements in glucose homeostasis in response to regular exercise are influenced by the PPARG Pro12Ala variant: results from the HERITAGE Family Study
}

\author{
S.-M. Ruchat • T. Rankinen • S. J. Weisnagel • T. Rice • \\ D. C. Rao • R. N. Bergman • C. Bouchard • L. Pérusse
}

Received: 21 May 2009/Accepted: 17 November 2009/Published online: 31 December 2009

(C) Springer-Verlag 2009

\begin{abstract}
Aims/hypothesis Exercise training improves glucose homeostasis, but large inter-individual differences are reported, suggesting a role of genetic factors. We investigated whether variants either confirmed or newly identified as diabetes susceptibility variants through genome-wide association studies (GWAS) modulate changes in phenotypes derived from an IVGTT in response to an endurance training programme.

Methods We analysed eight polymorphisms in seven type 2 diabetes genes (CDKAL1 rs7756992; CDKN2A and
\end{abstract}

S.-M. Ruchat $\cdot$ S. J. Weisnagel $\cdot$ L. Pérusse $(\square)$

Department of Social and Preventive Medicine,

PEPS - Laval University,

2300 rue de la Terrasse,

Quebec, QC, Canada G1V 0A6

e-mail: Louis.Perusse@kin.msp.ulaval.ca

S.-M. Ruchat · S. J. Weisnagel $\cdot$ L. Pérusse

Lipid Research Center, CHUL Research Center,

Quebec, QC, Canada

T. Rankinen $\cdot$ C. Bouchard

Human Genomics Laboratory,

Pennington Biomedical Research Center,

Baton Rouge, LA, USA

T. Rice $\cdot$ D. C. Rao

Division of Biostatistics, Washington University,

St Louis, MO, USA

R. N. Bergman

Department of Physiology and Biophysics,

Keck School of Medicine, University of Southern California,

Los Angeles, CA, USA

L. Pérusse

Nutraceuticals and Functional Foods Institute (INAF),

Quebec, QC, Canada
$C D K N 2 B$ rs10811661 and rs564398; HHEX rs7923837; IGF2BP2 rs4402960; KCNJ11 rs5215; PPARG rs1801282; and TCF7L2 rs7903146) in a maximum of 481 sedentary, non-diabetic white individuals, who participated in a 20 week endurance training programme. Associations were tested between the variants and changes in IVGTT-derived phenotypes.

Results The only evidence of association with training response was found with PPARG rs1801282 (Pro12Ala). We observed that Ala carriers experienced greater increase in overall glucose tolerance $(\Delta$ glucose disappearance index Ala/Ala $0.22 \pm 0.22$, Pro/Ala $0.14 \pm 0.06$, Pro/Pro $0.004 \pm$ $0.03 ; p=0.0008$ ), glucose effectiveness (Ala/Ala $0.28 \pm$ 0.41 , Pro/Ala $0.44 \pm 0.14$, Pro/Pro $0.09 \pm 0.06 ; p=0.004$ ), acute insulin response to glucose (Ala/Ala 64.21 \pm 37.73 , Pro/Ala $-11.92 \pm 40.30$, Pro/Pro $-46.30 \pm 14.70 ; p=0.03$ ) and disposition index (Ala/Ala 551.8 \pm 448.5 , Pro/Ala 534.6 \pm 218.3 , Pro/Pro -7.44 $\pm 88.18 ; p=0.003$ ).

Conclusions/interpretation Compared with Pro/Pro individuals, PPARG Ala carriers experienced greater improvements in glucose and insulin metabolism in response to regular endurance training. However, we did not find evidence of association between type 2 diabetes susceptibility variants recently identified through GWAS and glucose homeostasis response to exercise. Our results extend those of previous studies showing that Ala carriers appear to be more responsive to beneficial health effects of lifestyle interventions.

Keywords Diabetes susceptibility genes · IVGTT-derived phenotypes $\cdot$ Polymorphisms $\cdot$ Response to exercise
Abbreviations
$\mathrm{AIR}_{\mathrm{g}} \quad$ Acute insulin response to glucose
$\mathrm{D}_{\mathrm{I}} \quad$ Disposition index 


$\begin{array}{ll}\text { DPP } & \text { Diabetes Prevention Program } \\ \text { DPS } & \text { Finnish Diabetes Prevention Study } \\ \text { GWAS } & \text { Genome-wide association studies } \\ \text { HERITAGE } & \text { HEalth, RIsk factors, exercise Training, And } \\ & \text { GEnetics } \\ \mathrm{HWE} & \text { Hardy-Weinberg equilibrium } \\ \mathrm{IGR} & \text { Impaired glucose regulation } \\ \mathrm{K}_{\mathrm{g}} & \text { Glucose disappearance index } \\ \mathrm{S}_{\mathrm{g}} & \text { Glucose effectiveness } \\ \mathrm{S}_{\mathrm{I}} & \text { Insulin sensitivity index } \\ \mathrm{SNP}_{\dot{V}} & \text { Single nucleotide polymorphism } \\ \mathrm{O}_{2 \max } & \text { Maximal volume of oxygen consumption }\end{array}$

\section{Introduction}

Type 2 diabetes is the result of a complex interplay between genetic susceptibility and environmental factors, which causes two major pathophysiological features: impaired pancreatic beta cell function and insulin resistance [1]. Convincing data support the role of physical activity and weight loss in preventing type 2 diabetes [2]. Studies have demonstrated that exercise training may prevent type 2 diabetes by increasing insulin sensitivity and glucose tolerance $[3,4]$. However, there is considerable heterogeneity in the metabolic response to regular exercise. In this respect, the HERITAGE Family Study has reported large inter-individual differences in the changes of phenotypes derived from an IVGTT following a 20 -week exercise training programme [5]. Moreover, previous publications based on the same cohort suggested that genetic factors contribute to this heterogeneity [6-9].

Since 2007, several genome-wide association studies (GWAS) have been performed, leading to the discovery of several novel genes predisposing to type 2 diabetes, as well as confirming the implication of previously known candidate genes: CDKAL1, CDKN2A/B, IGF2BP2, HHEX, HNF1B, KCNJ11, PPARG, TCF7L2, SLC30A8, WFS1, ADAMTS9, CDC123, CAMK1D, JAZF1, NOTCH2, THADA, TSPAN8 and $L G R 5$ [10]. Since the response to lifestyle intervention aimed at reducing type 2 diabetes risk may be modulated by genetic factors, it is of great importance to identify patients who are most likely to benefit from regular endurance exercise and those who will not.

Of diabetes susceptibility polymorphisms, PPARG Pro12Ala has been most studied in interaction with lifestyle factors, but some conflicting results have been reported, with either no effect of the polymorphism on the response to intervention $[11,12]$ or beneficial health effects, albeit only in carriers of the Ala allele [13-16]. Few studies have investigated the impact of the other diabetes susceptibility variants on response to lifestyle interventions. TCF $7 L 2$ rs7903146 has been associated with improvement of insulin secretion and insulin sensitivity after lifestyle intervention in overweight children, carriers of the at-risk $\mathrm{T}$ allele being less responsive to the intervention [17]. However, analysis of data from the Diabetes Prevention Program (DPP) by Florez et al. failed to find significant gene $\times$ lifestyle intervention interaction with TCF7L2 rs7903146 affecting progression to type 2 diabetes [18]. More recently, Moore et al. [19] found that the $C D K N 2 A / B$ rs10811661 modified the effects of the DPP lifestyle intervention on insulin secretion and Brito et al. [12] reported that HNF1B rs4430796 significantly interacted with physical activity to influence impaired glucose tolerance risk and incident diabetes.

The purpose of this study was to investigate whether variants that have been either confirmed or newly identified as type 2 diabetes susceptibility variants through GWAS modulate changes in phenotypes derived from an IVGTT in response to 20 weeks of regular exercise training. This study is thought to be the first to assess the impact of the novel diabetes variants on glucose homeostasis changes in response to a fully standardised and monitored exercise training programme using IVGTT-derived measures of glucose homeostasis.

\section{Methods}

Study participants The HEealth, RIsk factors, exercise Training, And GEnetics (HERITAGE) Family Study is a multicentre exercise training study, whose main objective was to assess the role of genetic factors in cardiovascular, metabolic and hormonal responses to aerobic exercise training in sedentary families. The study design, sampling, inclusion and exclusion criteria have been described in detail elsewhere [20]. Briefly, the offspring were required to be $\geq 17$ years of age and the parents $<65$ years old. All participants were required to be sedentary at baseline, defined as not having engaged in regular vigorous physical activity over the previous 6 months, and free of chronic diseases that would prevent their participation in an exercise training programme. Although the HERITAGE Family Study recruited white and black participants, the present work reports data on white participants only. The baseline white cohort consisted of 503 participants, but only those who completed the 20 -week exercise intervention (i.e. did at least 58 of the prescribed 60 sessions) were included in the present study (481 participants, 233 of them men, from 98 nuclear families). Of the 481 participants, 184 were parents (93 men, 91 women) and 297 were adult offspring (140 men, 157 women). The protocol was approved by each of the institutional review boards of the different centres involved in the study (Arizona State University, Indiana University, Laval University, Penning- 
ton Biomedical Research Center, University of Minnesota, University of Texas at Austin, Texas A\&M University and Washington University). Informed consent was obtained from each participant.

Exercise training programme The 20-week exercise programme has been described in detail previously [20]. Briefly, the participants trained three times per week on cycle ergometers in the laboratory. Exercise intensity was customised for each participant, based on the heart rate to oxygen uptake relationship as measured at baseline. The participant started training at a heart rate corresponding to $55 \%$ of maximal volume of oxygen consumption $\left(\dot{V} \mathrm{O}_{2 \max }\right)$ for $30 \mathrm{~min}$ per session, gradually progressing to a heart rate corresponding to $75 \%$ of baseline $\dot{V} \mathrm{O}_{2 \max }$ for $50 \mathrm{~min}$ per session at the end of week 14. This level was sustained for the last 6 weeks. All training sessions were performed under supervision in each of the participating clinical centres. The participants were instructed not to change their dietary habits during the exercise programme.

Phenotype measurements All phenotypes were measured at baseline and after the exercise training programme on the day after the last exercise session. A frequently sampled IVGTT was administered in the morning after an overnight fast of $12 \mathrm{~h}$, as previously described [5]. The IVGTT protocol did not include the injection of intravenous insulin or tolbutamide. Insulin sensitivity index $\left(\mathrm{S}_{\mathrm{I}}\right)$, acute insulin response to glucose $\left(\mathrm{AIR}_{\mathrm{g}}\right)$, disposition index $\left(\mathrm{D}_{\mathrm{I}}\right)$ and glucose effectiveness $\left(\mathrm{S}_{\mathrm{g}}\right)$ were derived from the Minimal Model Millennium software [21]. $\mathrm{S}_{\mathrm{I}}$ measures the ability of an increment in plasma insulin to enhance the net disappearance of glucose from plasma and is used as a measure of insulin sensitivity. AIR $\mathrm{g}$, derived as the integrated area under the insulin curve between 0 and $10 \mathrm{~min}$ of the IVGTT, is used as a measure of insulin response. The $\mathrm{D}_{\mathrm{I}}$, calculated as $\mathrm{S}_{\mathrm{I}}$ multiplied by $\mathrm{AIR}_{\mathrm{g}}$, measures the ability of the pancreatic beta cell to compensate for changes in insulin sensitivity [22]. $\mathrm{S}_{\mathrm{g}}$ measures the ability of glucose itself to increase glucose disposal and to suppress endogenous glucose output independently of change in plasma insulin. Finally, glucose disappearance index $\left(\mathrm{K}_{\mathrm{g}}\right)$ estimates glucose disappearance based on the slope of the line derived from least-squares regression of the natural logarithm of plasma glucose from 10 to $60 \mathrm{~min}$ during the IVGTT, and was used as a measure of overall glucose tolerance. Plasma glucose was enzymatically determined using a reagent kit (Diagnostic Chemicals, Oxford, USA) and plasma insulin was measured by radioimmunoassay after polyethylene glycol separation [23]. Body mass index $\left(\mathrm{kg} / \mathrm{m}^{2}\right)$ was calculated as body weight divided by height squared. Waist girth was measured with a fibreglass anthropometric tape as described earlier [24].
Single nucleotide polymorphisms selection and genotyping Eight type 2 diabetes susceptibility variants identified through GWAS in 2007 were genotyped in the HERITAGE Family Study cohort (Table 1). Genotyping of the single nucleotide polymorphisms (SNPs) was done using GoldenGate chemistry (Illumina, San Diego, CA, USA) and array matrix technology (Sentrix) on a BeadStation 500GX (Illumina). Genotype calling was done with BeadStudio software (Illumina) and each call confirmed manually. Call rates were $100 \%$ for all eight SNPs as well as for all DNA samples. No Mendelian errors were found. For additional quality control purposes, five Centre d'Etude du Polymorphisme control DNA samples (NA10851, NA10854, NA10857, NA10860, NA10861; all included in the HapMap Caucasian panel, http://hapmap.ncbi.nlm.nih.gov/cgi-perl/ gbrowse/hapmap24_B36/) were genotyped in triplicates (distributed across 14 arrays). Concordance between the replicates as well as with the HapMap database genotypes was $100 \%$.

Statistical analyses Deviation from Hardy-Weinberg equilibrium (HWE), allele and genotype frequencies, and the linkage disequilibrium among polymorphisms were tested in unrelated individuals using the ALLELE procedure implemented in SAS Statistical Software package (version 9.1.3; SAS Institute, Cary, NC, USA). The pairwise linkage disequilibrium among the two SNPs in $C D K N 2 A / B$ was assessed by $r^{2}$ and $D^{\prime}$ [25]. Student paired $t$ tests were used to compare means of IVGTT-derived phenotypes at baseline and after exercise training (SAS Institute). The associations between the variants and changes in IVGTTderived phenotypes were tested using variance components and likelihood ratio test-based procedures implemented in the QTDT software package [26]. The total association model of the QTDT software uses a variance-components framework to combine a phenotypic mean model and estimates of additive genetic, residual genetic and residual environmental variances from a variance-covariance matrix into a single likelihood model. Evidence of association is evaluated by maximising the likelihoods under two conditions: the null hypothesis $\left(\mathrm{L}_{0}\right)$ restricts the additive genetic effect of the marker locus to zero $\left(\beta_{\mathrm{a}}=0\right)$, whereas the alternative hypothesis does not impose any restrictions to $\beta_{\mathrm{a}}$. The quantity of twice the difference of the $\log$ likelihoods between the null and the alternative hypotheses, i.e. $2\left[\ln \left(\mathrm{L}_{1}\right)-\ln \left(\mathrm{L}_{0}\right)\right]$, is asymptotically distributed as $\chi^{2}$ with one degree of freedom. A dominance effect can be tested in a similar manner, but the alternative hypothesis model includes estimates for additive $\left(\beta_{\mathrm{a}}\right)$ and dominance $\left(\beta_{\mathrm{a}} \times \beta_{\mathrm{a}}\right)$ genetic effects, and the likelihood-ratio test is based on $\chi^{2}$ distribution with 2 degrees of freedom [26]. The estimated effect (regression coefficient) of the variants and the proportion of the variance explained by the variants were also computed. The analyses were done on training 
response data adjusted for age, sex, baseline waist girth (when appropriate) and the respective baseline IVGTT measure. Fasting glucose and fasting insulin were logarithmically transformed and $\mathrm{S}_{\mathrm{I}}$, AIRg and $\mathrm{D}_{\mathrm{I}}$ were square root transformed to normalise their distribution prior to the analyses.

Nominal $p$ values are reported in Table 3, but for significant effects we also reported Bonferroni-adjusted $p$ values. This method assumes independent tests, and states that if $n$ independent tests are performed, then the corrected $\alpha$ level for each individual test is $\alpha^{\prime}=\alpha / n$. However, because not all of the tests performed were independent (we have correlations between phenotypes derived from the IVGTT; data not shown), we chose to correct the $\alpha$ level for the number of independent tests corresponding to the number of independent SNPs tested (i.e. eight). In doing so, the Bonferroni-based threshold for significance was 0.0063. Power calculations performed in the HERITAGE cohort for white participants indicated that we had $80 \%$ power to detect an association at the $0.05 \alpha$ level for a SNP accounting for as little as $1.6 \%$ of the phenotypic variation.

\section{Results}

Allele and genotype frequencies of the variants are presented in Table 1. All variants were in HWE $\left(\chi^{2}>\right.$
0.05). Table 2 displays the characteristics of the participants. Following the 20 -week exercise training programme, significant changes in adiposity and IVGTT-derived measures were observed in the participants.

Table 3 displays the estimated effects of the variants on changes in IVGTT-related phenotypes (regression coefficient $\beta$ ) and the proportion of total variance of the phenotypes explained by the variants. No effects of $C D K A L 1$ rs7756992, CDKN2A/B rs564398, HHEX rs7923837, IGF2BP2 rs4402960, KCNJ11 rs5215 and TCF7L2 rs4903146 polymorphisms were observed. A marginal effect of $C D K N 2 A / B$ rs10811661 on fasting glucose was found. Each copy of the at-risk allele was associated with an increase in fasting glucose level of $0.070 \mathrm{mmol} / 1$ ( $p=0.04$ unadjusted for multiple testing, $p=$ 0.32 adjusted for multiple testing) in response to exercise training. The only significant association that remained significant after adjustment for multiple testing was observed with PPARG Pro12Ala. Results show that the Pro12Ala polymorphism accounted for a significant proportion of the variance for changes in overall glucose tolerance $\left(\Delta \mathrm{K}_{\mathrm{g}}\right.$ $2.81 \% ; p=0.0008$ unadjusted, $p=0.006$ adjusted), $\Delta \mathrm{S}_{\mathrm{g}}$ $\left(1.83 \% ; p=0.004\right.$ unadjusted, $p=0.03$ adjusted), $\Delta \mathrm{AIR}_{\mathrm{g}}$ $\left(0.94 \% ; p=0.03\right.$ unadjusted, $p=0.24$ adjusted) and $\Delta D_{\mathrm{I}}$ ( $2.15 \% ; p=0.003$ unadjusted, $p=0.02$ adjusted), and that the Pro allele was negatively associated with changes in
Table 1 Allelic and genotypic frequencies of the variants
${ }^{\text {a }} C D K A L 1$ rs 7756992 is a proxy for rs $10946398\left(D^{\prime}=0.95\right.$, $R^{2}=0.68$ )

${ }^{\mathrm{b}}$ Linkage disequilibrium: $D^{\prime}=0.01, R^{2}=0.00$

\begin{tabular}{|c|c|c|c|c|c|}
\hline Genes & $n$ & Variants & Allele frequency & Genotype frequency & HWE $p$ value \\
\hline \multirow[t]{3}{*}{$C D K A L 1$} & 481 & rs $7756992^{\mathrm{a}}$ & $\mathrm{A}=0.75$ & $\mathrm{~A} / \mathrm{A}=0.56$ & 0.64 \\
\hline & & & $\mathrm{G}=0.25$ & $\mathrm{~A} / \mathrm{G}=0.39$ & \\
\hline & & & & $\mathrm{G} / \mathrm{G}=0.05$ & \\
\hline \multirow[t]{6}{*}{$C D K N 2 A / B^{\mathrm{b}}$} & 480 & rs564398 & $\mathrm{A}=0.61$ & $\mathrm{~A} / \mathrm{A}=0.36$ & 0.75 \\
\hline & & & $\mathrm{G}=0.39$ & $\mathrm{~A} / \mathrm{G}=0.49$ & \\
\hline & & & & $\mathrm{G} / \mathrm{G}=0.15$ & \\
\hline & 481 & rs10811661 & $\mathrm{A}=0.82$ & $\mathrm{~A} / \mathrm{A}=0.67$ & 0.34 \\
\hline & & & $\mathrm{G}=0.18$ & $\mathrm{~A} / \mathrm{G}=0.31$ & \\
\hline & & & & $\mathrm{G} / \mathrm{G}=0.02$ & \\
\hline \multirow[t]{3}{*}{ HHEX } & 481 & rs7923837 & $\mathrm{G}=0.59$ & $\mathrm{G} / \mathrm{G}=0.34$ & 0.67 \\
\hline & & & $\mathrm{A}=0.41$ & $\mathrm{G} / \mathrm{A}=0.50$ & \\
\hline & & & & $\mathrm{A} / \mathrm{A}=0.16$ & \\
\hline \multirow[t]{3}{*}{$I G F 2 B P 2$} & 481 & rs4402960 & $\mathrm{C}=0.70$ & $\mathrm{C} / \mathrm{C}=0.50$ & 0.55 \\
\hline & & & $\mathrm{A}=0.30$ & $\mathrm{C} / \mathrm{A}=0.40$ & \\
\hline & & & & $\mathrm{A} / \mathrm{A}=0.10$ & \\
\hline \multirow[t]{3}{*}{ KCNJ11 } & 481 & rs5215 & $\mathrm{A}=0.58$ & $\mathrm{~A} / \mathrm{A}=0.35$ & 0.44 \\
\hline & & & $\mathrm{G}=0.42$ & $\mathrm{~A} / \mathrm{G}=0.46$ & \\
\hline & & & & $\mathrm{G} / \mathrm{G}=0.19$ & \\
\hline \multirow[t]{3}{*}{ PPARG } & 481 & rs1801282 & $\mathrm{C}=0.88$ & $\mathrm{C} / \mathrm{C}=0.78$ & 0.72 \\
\hline & & & $\mathrm{G}=0.12$ & $\mathrm{C} / \mathrm{G}=0.21$ & \\
\hline & & & & $\mathrm{G} / \mathrm{G}=0.01$ & \\
\hline \multirow[t]{3}{*}{$T C F 7 L 2$} & 481 & rs7903146 & $\mathrm{G}=0.72$ & $\mathrm{G} / \mathrm{G}=0.51$ & 0.82 \\
\hline & & & $\mathrm{A}=0.28$ & $\mathrm{G} / \mathrm{A}=0.41$ & \\
\hline & & & & $\mathrm{A} / \mathrm{A}=0.08$ & \\
\hline
\end{tabular}


Table 2 Characteristics of the participants

\begin{tabular}{llllc}
\hline Phenotypes & Pre-training & Post-training & Changes & $p$ value \\
\hline$n($ men/women) & $481(233 / 248)$ & - & - & - \\
Age $($ years $)$ & $35.92 \pm 0.67$ & - & - & - \\
BMI $\left(\mathrm{kg} / \mathrm{m}^{2}\right)$ & $25.85 \pm 0.23$ & $25.75 \pm 0.23$ & $-0.09 \pm 0.03$ & 0.01 \\
Waist girth $(\mathrm{cm})$ & $90.40 \pm 0.68$ & $89.33 \pm 0.68$ & $-1.02 \pm 0.13$ & $<0.0001$ \\
Fasting glucose $(\mathrm{mmol} / \mathrm{l})$ & $5.05 \pm 0.03$ & $5.08 \pm 0.03$ & $0.02 \pm 0.02$ & 0.18 \\
Fasting insulin $(\mathrm{pmol} / \mathrm{l})$ & $65.78 \pm 1.84$ & $61.36 \pm 1.70$ & $-5.181 \pm 1.17$ & $<0.0001$ \\
$\mathrm{~S}_{\mathrm{I}}\left(\times 10^{-4} \mathrm{~min}^{-1}\left[\mu \mathrm{U} / \mathrm{ml}^{-1}\right)^{\mathrm{a}}\right.$ & $4.34 \pm 0.14$ & $4.57 \pm 0.13$ & $0.25 \pm 0.13$ & 0.006 \\
$\mathrm{AIR}_{\mathrm{g}}(\mathrm{pmol} / 1 \times 10 \mathrm{~min})$ & $664.72 \pm 24.37$ & $623.63 \pm 21.85$ & $-37.76 \pm 14.09$ & $<0.0001$ \\
$\mathrm{D}_{\mathrm{I}}^{\mathrm{b}}$ & $2,352.72 \pm 80.17$ & $2,440.41 \pm 87.03$ & $109.90 \pm 82.59$ & 0.83 \\
$\mathrm{~S}_{\mathrm{g}}($ per $100 \mathrm{~min})$ & $1.63 \pm 0.04$ & $1.79 \pm 0.05$ & $0.16 \pm 0.05$ & 0.002 \\
$\mathrm{~K}_{\mathrm{g}}($ per $100 \mathrm{~min})$ & $1.64 \pm 0.03$ & $1.67 \pm 0.03$ & $0.04 \pm 0.03$ & 0.17 \\
\hline
\end{tabular}

these phenotypes (or inversely, that the Ala allele is positively associated with changes in glucose homeostasis) (Table 3).

In line with the results presented in Table 3, Table 4 shows that following an i.v. glucose load carriers of the Ala allele exhibited greater improvements in overall glucose tolerance $\left(\Delta \mathrm{K}_{\mathrm{g}}\right.$ Ala/Ala $0.22 \pm 0.22$, Pro/Ala $0.14 \pm 0.06$, Pro/Pro $0.004 \pm 0.03 ; p=0.0008)$ and $\Delta \mathrm{S}_{\mathrm{g}}($ Ala/Ala $0.28 \pm$ 0.41 , Pro/Ala $0.44 \pm 0.14$, Pro/Pro $0.09 \pm 0.06 ; p=0.004$ ), and an increase in $\Delta \mathrm{AIR}_{\mathrm{g}}$ (Ala/Ala 64.21 \pm 37.73 , Pro/Ala $-11.92 \pm 40.30$, Pro/Pro $-46.30 \pm 14.70 ; p=0.03)$ and in $\Delta \mathrm{D}_{\mathrm{I}}$ (Ala/Ala 551.8 \pm 448.5 , Pro/Ala 534.6 \pm 218.3 , Pro/Pro $-7.44 \pm 88.18 ; p=0.003)$. To test whether the associations detected by us could be attributed to training-induced changes in waist circumference, analyses were repeated by adding changes in waist circumference as covariable in the model. Our results remained the same, suggesting that the effects of Pro12Ala on glucose homeostasis improvement after the training programme are independent of changes in waist circumference. Additional analyses (results not shown) on glucose and insulin levels at selected time points during the IVGTT revealed that, compared with Pro/Pro homozygotes, Ala carriers presented greater reductions in glucose levels at $30(p=0.002$ unadjusted, $p=0.02$ adjusted), 45 ( $p=0.0009$ unadjusted, $p=0.007$ adjusted), 60 ( $p=0.003$ unadjusted, $p=0.02$ adjusted) and $90(p=0.04$ unadjusted, $p=0.26$ adjusted) min after the i.v. glucose load. No association was found with insulin levels at selected time points during the IVGTT. Even though carriers of the at-risk Pro/Pro genotype experienced significantly less improvement in glucose tolerance and $\mathrm{S}_{\mathrm{g}}$ than Ala carriers in response to exercise training, they nonetheless showed evidence of favourable changes. Indeed, changes in adiposity (BMI and waist girth), insulin sensitivity (fasting insulin, 30, 45, 60, 90, 120 and $180 \mathrm{~min}$ insulin levels), insulin response $\left(\mathrm{AIR}_{\mathrm{g}}\right)$ and glucose tolerance (120 and $180 \mathrm{~min}$ glucose levels) were significantly different from zero (results not shown).

\section{Discussion}

Genome-wide association studies recently identified novel variants associated with type 2 diabetes risk in addition to confirming the implication of previously well-known susceptibility genes [27-33]. From public health and clinical perspectives, it is important to evaluate whether carriers of diabetes susceptibility alleles can benefit from regular physical activity. We therefore investigated whether these diabetes susceptibility variants modulate changes in glucose homeostasis in response to a supervised exercise training programme.

The stronger evidence of an association with training response was found with PPARG Pro12Ala. The present study showed that in response to exercise training, $P P A R G$ Ala carriers experienced greater increases in overall glucose tolerance, $\mathrm{S}_{\mathrm{g}}, \mathrm{AIR}_{\mathrm{g}}$ and $\mathrm{D}_{\mathrm{I}}$ than carriers of the Pro/Pro genotype. From a biological point of view, insulin sensitivity and insulin secretion are distinct pathways that interact to modulate glucose metabolism and tolerance. The enhancement of overall glucose tolerance observed in Ala carriers was explained by an improvement in beta cell function, since we observed an increase in insulin response to glucose and in the $\mathrm{D}_{\mathrm{I}}$. Interestingly, we also observed that in response to regular endurance training, Ala carriers experienced greater improvements in $S_{g}$, i.e. the ability of glucose itself to increase glucose disposal and suppress endogenous glucose output independently of changes in plasma insulin levels. The fact that Ala carriers presented greater reductions in glucose levels at 30, 45, 60 and 90 min after the i.v. glucose load than Pro/Pro individuals, while no differences were observed for the corresponding changes in insulin levels, suggests better $\mathrm{S}_{\mathrm{g}}$. Importantly, we found that although Ala carriers exhibited greater improvements in glucose homeostasis in response to endurance training than Pro/Pro carriers, the latter still improved their metabolic profile. From a public health perspective, this is clearly important. It is well established that the Pro/Pro 
Table 3 Summary of associations between the variants and changes in adiposity and IVGTT-derived phenotypes

\begin{tabular}{|c|c|c|c|}
\hline Variables per variant & Estimated effect $(\beta)$ & Explained variance $(\%)$ & $p$ value \\
\hline \multicolumn{4}{|l|}{$C D K A L 1$ rs7756992 $\mathrm{A}>\mathrm{G}^{*}$} \\
\hline BMI $\left(\mathrm{kg} / \mathrm{m}^{2}\right)$ & -0.056 & 0.21 & 0.34 \\
\hline Waist girth $(\mathrm{cm})$ & -0.131 & 0.08 & 0.50 \\
\hline Fasting glucose $(\mathrm{mmol} / \mathrm{l})$ & 0.037 & 0.40 & 0.25 \\
\hline Fasting insulin (pmol/1) & 1.972 & 0.30 & 0.28 \\
\hline $\mathrm{S}_{\mathrm{I}}\left(\times 10^{-4} \min ^{-1}[\mu \mathrm{U} / \mathrm{ml}]^{-1}\right)^{\mathrm{a}}$ & 0.367 & 0.91 & 0.06 \\
\hline $\mathrm{AIR}_{\mathrm{g}}(\mathrm{pmol} / 1 \times 10 \mathrm{~min})$ & 20.946 & 0.24 & 0.30 \\
\hline $\mathrm{D}_{\mathrm{I}}^{\mathrm{b}}$ & 141.39 & 0.31 & 0.25 \\
\hline $\mathrm{S}_{\mathrm{g}}($ per $100 \mathrm{~min})$ & 0.000 & 0.01 & 0.84 \\
\hline $\mathrm{K}_{\mathrm{g}}($ per $100 \mathrm{~min})$ & 0.044 & 0.34 & 0.24 \\
\hline \multicolumn{4}{|c|}{$C D K N 2 A / B$ rs10811661 $\mathrm{A}^{*}>\mathrm{G}\left(\right.$ or $\left.\mathrm{T}^{*}>\mathrm{C}\right)$} \\
\hline BMI $\left(\mathrm{kg} / \mathrm{m}^{2}\right)$ & 0.025 & 0.03 & 0.72 \\
\hline Waist girth $(\mathrm{cm})$ & 0.145 & 0.08 & 0.51 \\
\hline Fasting glucose $(\mathrm{mmol} / \mathrm{l})$ & 0.070 & 1.16 & $0.04(0.32)$ \\
\hline Fasting insulin (pmol/l) & -0.470 & 0.01 & 0.82 \\
\hline $\mathrm{S}_{\mathrm{I}}\left(\times 10^{-4} \min ^{-1}[\mu \mathrm{U} / \mathrm{ml}]^{-1}\right)^{\mathrm{a}}$ & 0.257 & 0.35 & 0.28 \\
\hline $\mathrm{AIR}_{\mathrm{g}}(\mathrm{pmol} / 1 \times 10 \mathrm{~min})$ & 2.590 & 0.00 & 0.89 \\
\hline $\mathrm{D}_{\mathrm{I}}^{\mathrm{b}}$ & 43.250 & 0.02 & 0.81 \\
\hline $\mathrm{S}_{\mathrm{g}}($ per $100 \mathrm{~min})$ & -0.001 & 0.38 & 0.31 \\
\hline $\mathrm{K}_{\mathrm{g}}($ per $100 \mathrm{~min})$ & -0.034 & 0.16 & 0.46 \\
\hline \multicolumn{4}{|l|}{$C D K N 2 A / B$ rs564398 $A^{*}>\mathrm{G}$} \\
\hline BMI $\left(\mathrm{kg} / \mathrm{m}^{2}\right)$ & 0.095 & 0.77 & 0.08 \\
\hline Waist girth (cm) & 0.352 & 0.73 & 0.08 \\
\hline Fasting glucose $(\mathrm{mmol} / \mathrm{l})$ & -0.023 & 0.20 & 0.42 \\
\hline Fasting insulin (pmol/l) & -1.504 & 0.22 & 0.36 \\
\hline $\mathrm{S}_{\mathrm{I}}\left(\times 10^{-4} \min ^{-1}[\mu \mathrm{U} / \mathrm{ml}]^{-1}\right)^{\mathrm{a}}$ & -0.062 & 0.03 & 0.73 \\
\hline $\mathrm{AIR}_{\mathrm{g}}(\mathrm{pmol} / \mathrm{l} \times 10 \mathrm{~min})$ & 19.325 & 0.26 & 0.31 \\
\hline $\mathrm{D}_{\mathrm{I}}^{\mathrm{b}}$ & 150.859 & 0.44 & 0.22 \\
\hline $\mathrm{S}_{\mathrm{g}}($ per $100 \mathrm{~min})$ & -0.000 & 0.00 & 1.00 \\
\hline $\mathrm{K}_{\mathrm{g}}($ per $100 \mathrm{~min})$ & 0.011 & 0.03 & 0.75 \\
\hline \multicolumn{4}{|l|}{$H H E X$ rs7923837 $\mathrm{G}^{*}>\mathrm{A}$} \\
\hline BMI $\left(\mathrm{kg} / \mathrm{m}^{2}\right)$ & -0.018 & 0.03 & 0.72 \\
\hline Waist girth $(\mathrm{cm})$ & 0.000 & 0.00 & 1.00 \\
\hline Fasting glucose (mmol/l) & -0.003 & 0.00 & 0.75 \\
\hline Fasting insulin (pmol/l) & -1.991 & 0.40 & 0.24 \\
\hline $\mathrm{S}_{\mathrm{I}}\left(\times 10^{-4} \min ^{-1}[\mu \mathrm{U} / \mathrm{ml}]^{-1}\right)^{\mathrm{a}}$ & -0.234 & 0.48 & 0.19 \\
\hline $\mathrm{AIR}_{\mathrm{g}}(\mathrm{pmol} / 1 \times 10 \mathrm{~min})$ & -34.273 & 0.83 & 0.07 \\
\hline $\mathrm{D}_{\mathrm{I}}^{\mathrm{b}}$ & -220.55 & 0.97 & 0.06 \\
\hline $\mathrm{S}_{\mathrm{g}}($ per $100 \mathrm{~min})$ & 0.000 & 0.00 & 0.82 \\
\hline $\mathrm{K}_{\mathrm{g}}($ per $100 \mathrm{~min})$ & -0.050 & 0.56 & 0.16 \\
\hline \multicolumn{4}{|l|}{$I G F 2 B P 2$ rs4402960 C $>\mathrm{A}^{*}$} \\
\hline BMI $\left(\mathrm{kg} / \mathrm{m}^{2}\right)$ & -0.008 & 0.01 & 0.88 \\
\hline Waist girth (cm) & 0.110 & 0.06 & 0.63 \\
\hline Fasting glucose $(\mathrm{mmol} / \mathrm{l})$ & -0.031 & 0.33 & 0.22 \\
\hline Fasting insulin (pmol/l) & 1.796 & 0.28 & 0.30 \\
\hline $\mathrm{S}_{\mathrm{I}}\left(\times 10^{-4} \min ^{-1}[\mu \mathrm{U} / \mathrm{ml}]^{-1}\right)^{\mathrm{a}}$ & -0.292 & 0.65 & 0.10 \\
\hline $\operatorname{AIR}_{\mathrm{g}}(\mathrm{pmol} / 1 \times 10 \mathrm{~min})$ & -17.851 & 0.20 & 0.34 \\
\hline $\mathrm{D}_{\mathrm{I}}^{\mathrm{b}}$ & -211.803 & 0.78 & 0.08 \\
\hline $\mathrm{S}_{\mathrm{g}}($ per $100 \mathrm{~min})$ & -0.001 & 0.57 & 0.14 \\
\hline $\mathrm{K}_{\mathrm{g}}($ per $100 \mathrm{~min})$ & -0.028 & 0.15 & 0.40 \\
\hline
\end{tabular}


Table 3 (continued)

\begin{tabular}{|c|c|c|c|}
\hline Variables per variant & Estimated effect $(\beta)$ & Explained variance (\%) & $p$ value \\
\hline \multicolumn{4}{|l|}{ KCNJ11 rs5215 A > $\mathrm{G}^{*}$} \\
\hline BMI $\left(\mathrm{kg} / \mathrm{m}^{2}\right)$ & -0.003 & 0.00 & 0.95 \\
\hline Waist girth (cm) & 0.176 & 0.19 & 0.28 \\
\hline Fasting glucose $(\mathrm{mmol} / \mathrm{l})$ & -0.004 & 0.00 & 0.97 \\
\hline Fasting insulin (pmol/1) & -1.105 & 0.12 & 0.44 \\
\hline $\mathrm{S}_{\mathrm{I}}\left(\times 10^{-4} \min ^{-1}[\mu \mathrm{U} / \mathrm{ml}]^{-1}\right)^{\mathrm{a}}$ & 0.246 & 0.53 & 0.18 \\
\hline $\mathrm{AIR}_{\mathrm{g}}(\mathrm{pmol} / 1 \times 10 \mathrm{~min})$ & -22.974 & 0.38 & 0.17 \\
\hline $\mathrm{D}_{\mathrm{I}}^{\mathrm{b}}$ & -111.618 & 0.25 & 0.30 \\
\hline $\mathrm{S}_{\mathrm{g}}($ per $100 \mathrm{~min})$ & 0.001 & 0.22 & 0.35 \\
\hline $\mathrm{K}_{\mathrm{g}}($ per $100 \mathrm{~min})$ & 0.006 & 0.01 & 0.86 \\
\hline \multicolumn{4}{|l|}{ PPARG $\mathrm{rs} 1801282 \mathrm{C}^{*}>\mathrm{G}$} \\
\hline BMI $\left(\mathrm{kg} / \mathrm{m}^{2}\right)$ & -0.138 & 0.69 & 0.08 \\
\hline Waist girth (cm) & -0.223 & 0.12 & 0.38 \\
\hline Fasting glucose $(\mathrm{mmol} / \mathrm{l})$ & -0.023 & 0.08 & 0.53 \\
\hline Fasting insulin (pmol/1) & -3.954 & 0.66 & 0.09 \\
\hline $\mathrm{S}_{\mathrm{I}}\left(\times 10^{-4} \min ^{-1}[\mu \mathrm{U} / \mathrm{ml}]^{-1}\right)^{\mathrm{a}}$ & -0.151 & 0.08 & 0.65 \\
\hline $\mathrm{AIR}_{\mathrm{g}}(\mathrm{pmol} / \mathrm{l} \times 10 \mathrm{~min})$ & -56.335 & 0.94 & $0.03(0.24)$ \\
\hline $\mathrm{D}_{\mathrm{I}}^{\mathrm{b}}$ & -508.25 & 2.15 & $0.003(0.02)$ \\
\hline $\mathrm{S}_{\mathrm{g}}($ per $100 \mathrm{~min})$ & -0.003 & 1.83 & $0.004(0.03)$ \\
\hline $\mathrm{K}_{\mathrm{g}}($ per $100 \mathrm{~min})$ & -0.172 & 2.81 & $0.0008(0.006)$ \\
\hline \multicolumn{4}{|l|}{ TCF7L2 $\operatorname{rs} 7903146 \mathrm{G}>\mathrm{A}^{*}$} \\
\hline BMI $\left(\mathrm{kg} / \mathrm{m}^{2}\right)$ & -0.042 & 0.13 & 0.46 \\
\hline Waist girth $(\mathrm{cm})$ & -0.264 & 0.36 & 0.24 \\
\hline Fasting glucose $(\mathrm{mmol} / \mathrm{l})$ & -0.047 & 0.73 & 0.09 \\
\hline Fasting insulin (pmol/l) & -2.776 & 0.67 & 0.11 \\
\hline $\mathrm{S}_{\mathrm{I}}\left(\times 10^{-4} \min ^{-1}[\mu \mathrm{U} / \mathrm{ml}]^{-1}\right)^{\mathrm{a}}$ & -0.217 & 0.35 & 0.24 \\
\hline $\mathrm{AIR}_{\mathrm{g}}(\mathrm{pmol} / 1 \times 10 \mathrm{~min})$ & 7.747 & 0.04 & 0.69 \\
\hline $\mathrm{D}_{\mathrm{I}}^{\mathrm{b}}$ & -69.226 & 0.08 & 0.59 \\
\hline $\mathrm{S}_{\mathrm{g}}($ per $100 \mathrm{~min})$ & -0.001 & 0.26 & 0.30 \\
\hline $\mathrm{K}_{\mathrm{g}}($ per $100 \mathrm{~min})$ & -0.007 & 0.01 & 0.77 \\
\hline
\end{tabular}

Analyses were adjusted for age, sex, baseline waist girth (when appropriate) and the respective baseline value $p$ values are for the additive effect; those in parentheses are adjusted for multiple testing using the Bonferroni method

The estimated effect $(\beta)$ was calculated for the at-risk allele $(*)$

${ }^{\mathrm{a}}$ Units are from the MINMOD program [21]. To convert value to SI units $\left(\times 10^{-4} \mathrm{~min}^{-1}[\mathrm{pmol} / \mathrm{ml}]^{-1}\right)$, multiply by 0.167

${ }^{\mathrm{b}} \mathrm{D}_{\mathrm{I}}$ is calculated as $\mathrm{S}_{\mathrm{I}}$ units generated from the MINMOD program $\left(\times 10^{-4} \mathrm{~min}^{-1}[\mu \mathrm{U} / \mathrm{ml}]^{-1}\right)$ multiplied by $\mathrm{AIR}_{\mathrm{g}}(\mathrm{pmol} / 1 \times 10 \mathrm{~min})$

genotype is associated with increased risk of type 2 diabetes. Our finding therefore suggests that even if carriers of the Pro/ Pro genotype experience less improvement in type 2 diabetes-related phenotypes than Ala carriers, they still benefit from regular exercise and in doing so may attenuate their diabetes risk.

Several previous studies have examined the interactions of the PPARG Pro12Ala genotype with environmental and lifestyle factors, and their effect on diabetes-related metabolic phenotypes, as indicated in a recent review [34]. However, the study design and outcome phenotypes have been diverse and the results ambiguous. Two lifestyle (diet and physical activity) intervention studies reported conflicting results. Thus the Finnish Diabetes Prevention Study (DPS) [13], which reported an association between the PPARG Ala allele and progression to type 2 diabetes, showed that in the intervention group, carriers of the Ala allele lost more weight and none of them developed the disease, suggesting that beneficial changes in diet and physical activity may reverse the diabetogenic impact of the Ala allele. However, results from the DPP showed no differences in the response to lifestyle intervention among participants with the PPARG Pro12Ala genotype [11]. More recently, a large prospective study reported a nominal 
Table 4 Association between PPARG rs1801282 (Pro12Ala) and changes in adiposity and IVGTT-derived phenotypes

\begin{tabular}{|c|c|c|c|c|}
\hline Phenotypes & Pro/Pro $(n=381)$ & Pro/Ala $(n=92)$ & Ala/Ala $(n=8)$ & $p$ values \\
\hline BMI $\left(\mathrm{kg} / \mathrm{m}^{2}\right)$ & $-0.12 \pm 0.04$ & $0.045 \pm 0.08$ & $0.01 \pm 0.24$ & 0.08 \\
\hline Waist girth $(\mathrm{cm})$ & $-1.10 \pm 0.15$ & $-0.65 \pm 0.27$ & $-1.34 \pm 0.54$ & 0.38 \\
\hline Fasting glucose $(\mathrm{mmol} / \mathrm{l})$ & $0.007 \pm 0.02$ & $0.10 \pm 0.04$ & $-0.01 \pm 0.14$ & 0.53 \\
\hline Fasting insulin (pmol/1) & $-6.32 \pm 1.36$ & $-1.01 \pm 2.31$ & $-2.50 \pm 3.85$ & 0.09 \\
\hline $\mathrm{S}_{\mathrm{I}}\left(\times 10^{-4} \min ^{-1}[\mu \mathrm{U} / \mathrm{ml}]^{-1}\right)^{\mathrm{a}}$ & $0.22 \pm 0.15$ & $0.41 \pm 0.31$ & $0.04 \pm 0.46$ & 0.65 \\
\hline $\operatorname{AIR}_{\mathrm{g}}(\mathrm{pmol} / 1 \times 10 \mathrm{~min})$ & $-46.30 \pm 14.70$ & $-11.92 \pm 40.30$ & $64.21 \pm 37.73$ & $0.03(0.24)$ \\
\hline $\mathrm{D}_{1}^{\mathrm{b}}$ & $-7.44 \pm 88.18$ & $534.6 \pm 218.3$ & $551.8 \pm 448.5$ & $0.003(0.02)$ \\
\hline $\mathrm{S}_{\mathrm{g}}($ per $100 \mathrm{~min})$ & $0.09 \pm 0.06$ & $0.44 \pm 0.14$ & $0.28 \pm 0.41$ & $0.004(0.03)$ \\
\hline $\mathrm{K}_{\mathrm{g}}($ per $100 \mathrm{~min})$ & $0.004 \pm 0.03$ & $0.14 \pm 0.06$ & $0.22 \pm 0.22$ & $0.0008(0.006)$ \\
\hline
\end{tabular}

Data are means $\pm \mathrm{SE}$

Analyses were adjusted for age, sex, baseline waist girth (when appropriate) and the respective baseline value

$p$ values are for the additive effect; those in parentheses are adjusted for multiple testing using the Bonferroni method

${ }^{\mathrm{a}}$ Units are from the MINMOD program [21]. To convert value to SI units $\left(\times 10^{-4} \mathrm{~min}^{-1}[\mathrm{pmol} / \mathrm{ml}]^{-1}\right)$, multiply by 0.167

${ }^{\mathrm{b}} \mathrm{D}_{\mathrm{I}}$ is calculated as $\mathrm{S}_{\mathrm{I}}$ generated from the MINMOD program $\left(\times 10^{-4} \mathrm{~min}^{-1}[\mu \mathrm{U} / \mathrm{ml}]^{-1}\right)$ multiplied by $\mathrm{AIR}_{\mathrm{g}}(\mathrm{pmol} / 1 \times 10 \mathrm{~min})$

interaction effect for Pro12Ala on impaired glucose regulation (IGR), the Ala allele being associated with a reduced risk of IGR, but only in inactive individuals [12]. However, this finding did not withstand correction for multiple testing. Results of gene $\times$ exercise training interactions have been more consistent in showing Alaallele carriers to be more sensitive to the positive effects of exercise on metabolic profile. A study of sedentary diabetic men reported that after 3 months of supervised aerobic and resistance exercises, greater improvements in fasting glycaemia were observed in Ala carriers [14]. Weiss et al. studied sedentary overweight, but otherwise healthy individuals, who underwent 6 months of supervised aerobic training. They found that male carriers of the Ala allele were more responsive to the insulin-sensitising effect of endurance training than carriers of the Pro/Pro genotype [16]. Similarly, Kahara et al. [15] reported that after 3 months of aerobic exercise training, healthy Japanese men carrying the Ala allele experienced greater improvements in insulin sensitivity than those carrying the Pro/Pro genotype.

A systematic investigation of the results of the existing literature on the effects of PPARG Pro12Ala on the metabolic response to different types of lifestyle intervention [11-16] showed that consistent findings have been reported in exercise training studies [14-16] (i.e. the Ala carriers are more responsive than the Pro/Pro to beneficial effects of exercise training in terms of glucose homeostasis improvement), even if the studies were performed on different populations in terms of age, sex, ethnicity, BMI or glucose tolerance status. The strength of a supervised exercise programme is that it encourages participant compliance and provides the same exercise stimulus to all of them, therefore guaranteeing that inter-individual varia- tion in glucose homeostasis changes cannot be due to variation in exercise stimulus. Given the consistent results of such studies [14-16], we speculate that the standardised stimulus attenuated the impact of other potential confounding factors such as age, sex, ethnicity, BMI and glucose tolerance status on the metabolic response. Combined lifestyle intervention studies (physical activity and nutrition) like the DPS and the DPP have reported conflicting results [11, 13]. Results of the DPS [13] are concordant with findings of exercise training studies in showing an effect of PPARG Pro12Ala on reduction of diabetes risk following the intervention, whereas the DPP [11] showed no effect. The design and type of intervention of the DPS and the DPP are very similar. However, the DPP cohort includes individuals of different ethnic origin (Whites, African-American, Hispanic, Asian-American, AmericanIndian), while the DPS cohort only includes individuals from Finland. It has been shown that the effect of Pro12Ala on obesity and diabetes risk varies by ethnicity [35, 36]. We can therefore speculate that the effect of the polymorphism on diabetes risk reduction in response to a lifestyle intervention also varies by ethnicity and may explain the conflicting results. Finally, a prospective study assessing physical activity level by questionnaire reported opposite findings, with physically active individuals carrying the Ala allele at higher risk of impaired glucose metabolism [12]. However, this positive finding was no longer significant after correction for multiple testing, suggesting that the association may be attributable to chance. This overview highlights that different variables such as the exposure measurement, the outcome measurement, the study design, the population and the statistical methods should all be taken into account when comparing the results of several studies and may explain the conflicting results sometimes observed. 
Functional studies might explain why Ala-allele carriers are more sensitive to the effects of exercise, as suggested by the results of the present study. PPARG is particularly expressed in white adipose tissue and its effects on glucose homeostasis are most likely to be attributable to altered adipose tissue metabolism [37]. Studies [38, 39] have suggested that the Ala allele reduces the transcriptional activity of peroxisome proliferator-activated receptor gamma (PPARG), enhancing the ability of insulin to suppress lipolysis in adipocytes and leading to a decrease in release of NEFA into the circulation [40]. The Ala allele was also associated with a decrease in lipid oxidation, but an increase in glucose oxidation in lean participants during insulin stimulation [41]. In line with this, Adamo et al. reported lower plasma NEFA levels at baseline and after exercise training in Ala carriers than in the Pro/Pro homozygotes [14]. Reduced availability of NEFA would then permit glucose to be preferentially oxidised as a fuel source in muscle. In the context of the present study, we speculate that this metabolic effect of PPARG could explain the greater improvement in glucose tolerance and $\mathrm{Sg}$ in Ala carriers in response to exercise.

As for the other variants, we found no association, except for a nominal effect of $C D K N 2 A / B$ rs 10811661, with each copy of the protective allele associated with a decrease in fasting glucose levels of $0.070 \mathrm{mmol} / \mathrm{l}$ (Table 3) after the exercise training programme. The nature of the effect is consistent with those reported in two previous studies. The report from the DPP [19] showed that $C D K N 2 A / B$ rs10811661 marginally modified the effect of the lifestyle intervention on beta cell function improvement, the improvement being greater in participants with the lowrisk genotype than in those with the high-risk genotype after lifestyle modification. Accordingly, the study of Brito et al. [12] reported a nominally significant effect of gene $\times$ physical activity interaction on $2 \mathrm{~h}$ glucose levels for $C D K N 2 A / B$ rs10811661, the protective allele being associated with lower $2 \mathrm{~h}$ glucose levels, albeit only in physically active individuals. In the same study [12], the only interaction effect that withstands correction for multiple testing was that with $H N F 1 B$ rs4430796, the A allele (protective allele) being associated with lower risk of IGR and incident diabetes, but only in physically inactive participants. Taken together, these results suggest that the majority of the novel diabetes susceptibility variants do not interact with physical activity/exercise to modulate changes in type 2 diabetes risk.

Since only few studies have assessed the effects of interaction between the novel diabetes susceptibility variants and physical activity/exercise on type 2 diabetes risk profile, further studies are needed before drawing firm conclusions. Little is known about the function of these variants, and examining their effects in the context of an exercise intervention might help elucidate their role in diabetes. Furthermore, from public health and clinical perspectives, such studies are important to better understand the contribution of genetic factors to individual differences in response to regular physical activity/exercise. They may help identify individuals who are likely to benefit from being physically active, as well as those for whom alternative interventions such as dietary changes or pharmacological treatment might be more effective.

Our study has several strengths that emphasise its unique contribution. First, the exercise programme was designed to provide the same exercise stimulus in terms of frequency, duration and relative intensity to all participants, and all exercise sessions were performed under supervision. These facts guarantee that inter-individual variation in glucose homeostasis changes could not be due to variation in exercise dose. Second, the duration of the programme (20 weeks) was long enough to produce significant physiological adaptations to regular exercise. Third, the participants were free of disease and sedentary at baseline, eliminating potential confounding due to differences in baseline chronic diseases, medication use or activity levels. Fourth, measures of glucose homeostasis and metabolism were derived from an IVGTT, a method that is well validated, widely used to investigate glucose metabolism in vivo and allows determination of major components of glucose metabolism in dynamic conditions. Finally, our sample size is among the largest of published exercise training studies reporting evidence of gene $\times$ exercise interaction for phenotypes related to glucose and insulin metabolism.

Despite its strengths, our study also had some limitations. One potential limitation is the lack of a control group. The HERITAGE Family Study was originally designed to investigate the role of genetic factors in cardiovascular, metabolic and hormonal responses to exercise training, so a control group was not deemed necessary. It is therefore difficult to conclude whether the observed improvement in IVGTT-related phenotypes was due to exercise training or to changes in other correlates of glucose homeostasis. Second, participants were encouraged not to change dietary habits in this trial, but we have no objective measures of possible changes in free-living behaviour during the intervention. However, we do not believe that changes that might have occurred in dietary fat intake during the 20 -week period of exercise training would be of sufficient magnitude to confound the changes in glucose homeostasis brought about by the exercise training programme. Finally, the effects of the Ala allele on glucose homeostasis improvement could be due to false positive results. However, not only was our study sufficiently powered to detect significant effects, but our results also remained significant after multiple testing correction. 
In summary, the results of the present study suggest that changes in overall glucose tolerance, $\mathrm{S}_{\mathrm{g}}$ and pancreatic beta cell function in response to regular exercise may be modulated by the PPARG Pro12Ala polymorphism. Our results showed that Ala carriers experienced greater improvements in glucose homeostasis, thus extending previous findings that Ala carriers are more responsive to the positive effects of lifestyle modifications on metabolic variables associated with type 2 diabetes.

Acknowledgements The HERITAGE Family Study has been supported over the years by the National Heart, Lung, and Blood Institute (Grants HL-45670, HL-47317, HL-47323, HL-47327 and HL-47321). The study continues to be supported by HL-45670. Thanks are expressed to A. S. Leon, J. S. Skinner and J. H. Wilmore for their contributions to the HERITAGE Family Study. C. Bouchard is partially supported by the George A. Bray Chair in Nutrition. S.-M. Ruchat is supported by a scholarship from the Canadian Diabetes Association.

Duality of interest The authors declare that there is no duality of interest associated with this manuscript.

\section{References}

1. Permutt MA, Wasson J, Cox N (2005) Genetic epidemiology of diabetes. J Clin Invest 115:1431-1439

2. Madden SG, Loeb SJ, Smith CA (2008) An integrative literature review of lifestyle interventions for the prevention of type II diabetes mellitus. J Clin Nurs 17:2243-2256

3. Praet SF, van Loon LJ (2007) Optimizing the therapeutic benefits of exercise in type 2 diabetes. J Appl Physiol 103:1113-1120

4. Yates T, Khunti K, Bull F, Gorely T, Davies MJ (2007) The role of physical activity in the management of impaired glucose tolerance: a systematic review. Diabetologia 50:1116-1126

5. Boule NG, Weisnagel SJ, Lakka TA et al (2005) Effects of exercise training on glucose homeostasis: the HERITAGE Family Study. Diabetes Care 28:108-114

6. Lakka TA, Rankinen T, Weisnagel SJ et al (2004) Leptin and leptin receptor gene polymorphisms and changes in glucose homeostasis in response to regular exercise in nondiabetic individuals: the HERITAGE family study. Diabetes 53:1603-1608

7. Lakka TA, Rankinen T, Weisnagel SJ et al (2003) A quantitative trait locus on $7 \mathrm{q} 31$ for the changes in plasma insulin in response to exercise training: the HERITAGE Family Study. Diabetes 52:1583-1587

8. Teran-Garcia M, Rankinen T, Rice T et al (2007) Variations in the four and a half LIM domains 1 gene (FHL1) are associated with fasting insulin and insulin sensitivity responses to regular exercise. Diabetologia 50:1858-1866

9. Teran-Garcia M, Santoro N, Rankinen T et al (2005) Hepatic lipase gene variant $-514 \mathrm{C}>\mathrm{T}$ is associated with lipoprotein and insulin sensitivity response to regular exercise: the HERITAGE Family Study. Diabetes 54:2251-2255

10. Florez JC (2008) Clinical review: the genetics of type 2 diabetes: a realistic appraisal in 2008. J Clin Endocrinol Metab 93:4633-4642

11. Florez JC, Jablonski KA, Sun MW et al (2007) Effects of the type 2 diabetes-associated PPARG P12A polymorphism on progression to diabetes and response to troglitazone. J Clin Endocrinol Metab 92:1502-1509
12. Brito EC, Lyssenko V, Renstrom F et al (2009) Previously associated type 2 diabetes variants may interact with physical activity to modify the risk of impaired glucose regulation and type 2 diabetes: a study of 16,003 Swedish adults. Diabetes 58:14111418

13. Lindi VI, Uusitupa MI, Lindstrom J et al (2002) Association of the Pro12Ala polymorphism in the PPAR-gamma2 gene with 3-year incidence of type 2 diabetes and body weight change in the Finnish Diabetes Prevention Study. Diabetes 51:2581-2586

14. Adamo KB, Sigal RJ, Williams K, Kenny G, Prud'homme D, Tesson F (2005) Influence of Pro12Ala peroxisome proliferatoractivated receptor gamma2 polymorphism on glucose response to exercise training in type 2 diabetes. Diabetologia 48:15031509

15. Kahara T, Takamura T, Hayakawa $T$ et al (2003) PPARgamma gene polymorphism is associated with exercise-mediated changes of insulin resistance in healthy men. Metabolism 52:209-212

16. Weiss EP, Kulaputana O, Ghiu IA et al (2005) Endurance traininginduced changes in the insulin response to oral glucose are associated with the peroxisome proliferator-activated receptorgamma2 Pro12Ala genotype in men but not in women. Metabolism 54:97-102

17. Reinehr T, Friedel S, Mueller TD, Toschke AM, Hebebrand J, Hinney A (2008) Evidence for an influence of TCF7L2 polymorphism rs7903146 on insulin resistance and sensitivity indices in overweight children and adolescents during a lifestyle intervention. Int J Obes (Lond) 32:1521-1524

18. Florez JC, Jablonski KA, Bayley $\mathrm{N}$ et al (2006) TCF7L2 polymorphisms and progression to diabetes in the Diabetes Prevention Program. N Engl J Med 355:241-250

19. Moore AF, Jablonski KA, McAteer JB et al (2008) Extension of type 2 diabetes genome-wide association scan results in the diabetes prevention program. Diabetes 57:2503-2510

20. Bouchard C, Leon AS, Rao DC, Skinner JS, Wilmore JH, Gagnon J (1995) The HERITAGE family study. Aims, design, and measurement protocol. Med Sci Sports Exerc 27:721-729

21. Boston RC, Stefanovski D, Moate PJ, Sumner AE, Watanabe RM, Bergman RN (2003) MINMOD Millennium: a computer program to calculate glucose effectiveness and insulin sensitivity from the frequently sampled intravenous glucose tolerance test. Diabetes Technol Ther 5:1003-1015

22. Bergman RN, Ader M, Huecking K, Van Citters G (2002) Accurate assessment of beta-cell function: the hyperbolic correction. Diabetes 51(Suppl 1):S212-S220

23. Desbuquois B, Aurbach GD (1971) Use of polyethylene glycol to separate free and antibody-bound peptide hormones in radioimmunoassays. J Clin Endocrinol Metab 33:732-738

24. Wilmore JH, Despres JP, Stanforth PR et al (1999) Alterations in body weight and composition consequent to $20 \mathrm{wk}$ of endurance training: the HERITAGE Family Study. Am J Clin Nutr 70:346352

25. Devlin B, Risch N (1995) A comparison of linkage disequilibrium measures for fine-scale mapping. Genomics 29:311-322

26. Abecasis GR, Cherny SS, Cookson WO, Cardon LR (2002) Merlin-rapid analysis of dense genetic maps using sparse gene flow trees. Nat Genet 30:97-101

27. WTCCC (2007) Genome-wide association study of 14,000 cases of seven common diseases and 3,000 shared controls. Nature 447:661-678

28. Gudmundsson J, Sulem P, Steinthorsdottir V et al (2007) Two variants on chromosome 17 confer prostate cancer risk, and the one in TCF2 protects against type 2 diabetes. Nat Genet 39:977983

29. Saxena R, Voight BF, Lyssenko V et al (2007) Genome-wide association analysis identifies loci for type 2 diabetes and triglyceride levels. Science 316:1331-1336 
30. Scott LJ, Mohlke KL, Bonnycastle LL et al (2007) A genomewide association study of type 2 diabetes in Finns detects multiple susceptibility variants. Science 316:1341-1345

31. Sladek R, Rocheleau G, Rung J et al (2007) A genome-wide association study identifies novel risk loci for type 2 diabetes. Nature 445:881-885

32. Steinthorsdottir V, Thorleifsson G, Reynisdottir I et al (2007) A variant in CDKAL1 influences insulin response and risk of type 2 diabetes. Nat Genet 39:770-775

33. Zeggini E, Weedon MN, Lindgren CM et al (2007) Replication of genome-wide association signals in UK samples reveals risk loci for type 2 diabetes. Science 316:1336-1341

34. Franks PW, Mesa JL, Harding AH, Wareham NJ (2007) Genelifestyle interaction on risk of type 2 diabetes. Nutr Metab Cardiovasc Dis 17:104-124

35. Ludovico O, Pellegrini F, Di Paola R et al (2007) Heterogeneous effect of peroxisome proliferator-activated receptor gamma2 Ala12 variant on type 2 diabetes risk. Obesity (Silver Spring) 15:1076-1081

36. Tonjes A, Scholz M, Loeffler M, Stumvoll M (2006) Association of Pro12Ala polymorphism in peroxisome proliferator-activated receptor gamma with pre-diabetic phenotypes: meta-analysis of 57 studies on nondiabetic individuals. Diabetes Care 29:2489-2497

37. Stumvoll M, Haring H (2002) The peroxisome proliferatoractivated receptor-gamma2 Pro12Ala polymorphism. Diabetes 51:2341-2347

38. Deeb SS, Fajas L, Nemoto M et al (1998) A Pro12Ala substitution in PPARgamma2 associated with decreased receptor activity, lower body mass index and improved insulin sensitivity. Nat Genet 20:284-287

39. Masugi J, Tamori Y, Mori H, Koike T, Kasuga M (2000) Inhibitory effect of a proline-to-alanine substitution at codon 12 of peroxisome proliferator-activated receptor-gamma 2 on thiazolidinedioneinduced adipogenesis. Biochem Biophys Res Commun 268:178-182

40. Stumvoll M, Wahl HG, Loblein K et al (2001) Pro12Ala polymorphism in the peroxisome proliferator-activated receptorgamma2 gene is associated with increased antilipolytic insulin sensitivity. Diabetes 50:876-881

41. Thamer C, Haap M, Volk A et al (2002) Evidence for greater oxidative substrate flexibility in male carriers of the Pro 12 Ala polymorphism in PPARgamma2. Horm Metab Res 34:132-136 